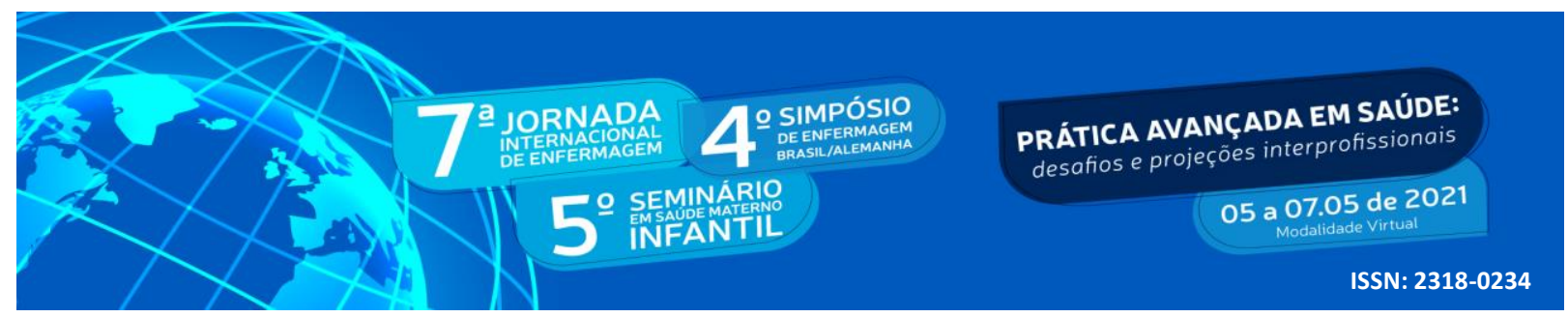

DOI: http://doi.org/10.48195/jie2021-119

\title{
SISTEMATIZAÇÃO DA ASSISTÊNCIA DE ENFERMAGEM: OLHAR À LUZ DO PENSAMENTO DA COMPLEXIDADE ${ }^{1}$
}

\section{Carolina Fernandes da Rocha² ${ }^{2}$ Leandro da Silva de Medeiros ${ }^{3}$; Laura Corrêa Ferraz ${ }^{4}$; Estevan Guterres de Oliveira ${ }^{5}$; Dirce Stein Backes ${ }^{6}$}

\section{RESUMO}

Objetivo: desenvolver a Sistematização da Assistência de Enfermagem (SAE) com uma transexual à luz do pensamento da Complexidade de Edgar Morin. Método: trata-se de uma narrativa investigativa educativa, desenvolvida com base nas etapas da Sistematização da Assistência de Enfermagem com uma transexual fictícia. Resultados: evidenciou-se a necessidade de maior foco no contexto social das travestis, considerando ser uma população socialmente discriminada e, frequentemente, exposta a violência. Conclusão: conclui-se que o desenvolvimento da SAE possibilitou um olhar singularizado às necessidades da travesti e a compreensão do papel social do Enfermeiro, que vai além da identificação de um problema, mas que requer intervenções proativas relacionadas à promoção da saúde.

Palavras-chave: Atenção Integral à Saúde; Processo de Enfermagem; Transexualidade.

\begin{abstract}
Objective: to develop a Nursing Care Systematization (SAE) with a transsexual in the light of Edgar Morin's Complexity thinking. Method: it is an educational investigative narrative, developed based on the stages of the Nursing Care Systematization with a transsexual. Results: there was a need for greater focus on the social context of transvestites, considering that they are a socially discriminated population and, frequently, exposed to violence. Conclusion: it is concluded that the development of SAE enabled a singular look at the needs of the transvestite and the understanding of the social role of the Nurse, which goes beyond the identification of a problem, but which requires proactive operations related to health promotion.
\end{abstract}

Key Words: Comprehensive Health Care; Nursing Process; Transsexuality.

\footnotetext{
${ }^{1}$ Trabalho desenvolvido na Disciplina de Fundamentos Teórico-Filosóficos da Enfermagem - Universidade Franciscana.

2 Estudante do Curso de Enfermagem da Universidade Franciscana. E-mail: carolinafernandessm@gmail.com

3 Estudante do Curso de Enfermagem da Universidade Franciscana. E-mail: leandro.medeiros@ufn.edu.br

${ }^{4}$ Estudante do Curso de Enfermagem da Universidade Franciscana. E-mail: lauracfbiomed@ gmail.com

${ }^{5}$ Estudante do Curso de Enfermagem da Universidade Franciscana. E-mail: estevanguterres@ gmail.com

${ }^{6}$ Orientadora. Doutora em Enfermagem. Docente do Curso de Enfermagem e Coordenadora do Mestrado Profissional Saúde Materno Infantil - Universidade Franciscana. E-mail: backesdirce@ ufn.edu.br
} 


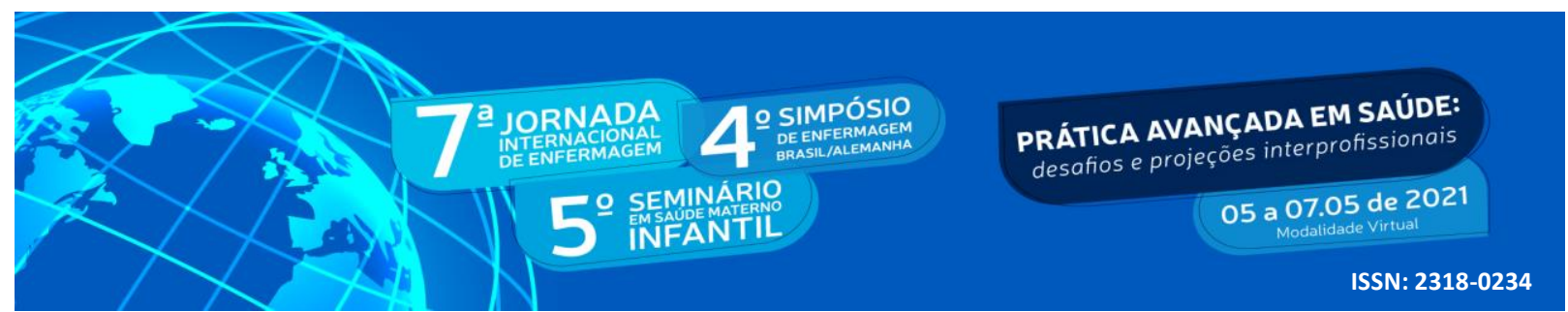

\section{INTRODUÇÃO}

O Brasil é considerado um país emergente e que se encontra em processo de desenvolvimento. Os índices que retratam o crescimento social destacam que a escolaridade brasileira precisa evoluir em comparação aos países de primeiro mundo. Diante disso, destacase que tal situação é gerada pela busca de conhecimentos além do que é transmitido na televisão e em redes sociais, gerando um indivíduo restrito ao conhecimento de senso comum ou até ser receptor de informações incorretas (CURY, 2012).

Segundo Morin (2015, p. 13) afirma que "o saber se tornou cada vez mais esotérico (acessível somente aos especialistas) e anônimos (quantificados e formalizados)". Com isso, percebesse o restrito acesso ao conhecimento e a limitação de tal processo. Nessa direção Morin (2015 p.24) identifica que "uma cabeça bem-feita é uma cabeça apta a organizar os conhecimentos e, com isso, evitar sua acumulação estéril”".

À frente dessa discussão sobre o conhecimento é importante ressaltar, que a temática sexualidade é ainda um campo pouco explorado. Nessa perspectiva fica clara quando se coloca qualquer variante diferente do "normal" como representação da homossexualidade, processo comum ao iniciar um debate que envolva a transexualidade.

A transexualidade para Bento (2014) deve considerar os desdobramentos da sexualidade, gênero e identidade de gênero. É evidente que este campo perpassa por diversas controvérsias e intriga a sociedade, por gerar dúvidas, preconceito e principalmente por não ser possível compreender os conflitos internos vivenciados pela pessoa transexual.

Para Edgar Morin (2015 p. 362).

$\mathrm{Na}$ espécie Homo sapiens, o gênero masculino e o gênero feminino manifestam sua diferença não apenas pelos órgãos sexuais, mas também nos traços sexuais secundários (barba masculina, busto e quadris femininos) e por um ligeiro dimorfismo da estrutura.

Ademais, as diferenças traçadas entre homens e mulheres, heterossexuais e homossexuais foram/são montadas historicamente, diante do processo de evolução da sociedade bem como os princípios, valores culturais e sociais. Logo, é preciso que novos estudos sejam realizados, a fim de ampliar a compreensão teórico-prática sobre o tema. 


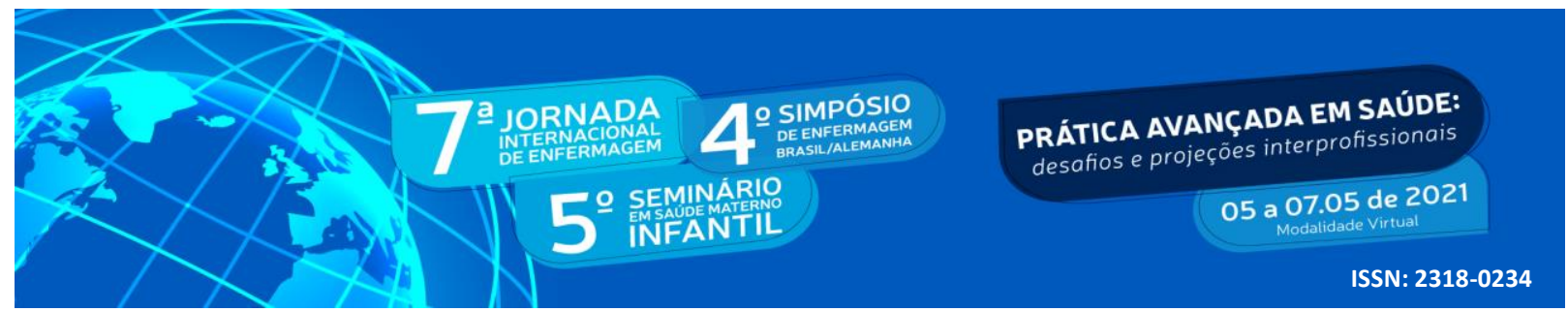

A Sistematização da Assistência de Enfermagem (SAE), nesse processo, se constitui em metodologia capaz de apreender determinados fenômenos, em sua forma singular e multidimensional. Regulamentada como método que organiza o trabalho profissional, a SAE possibilita a implementação do Processo de Enfermagem (PE), instrumento metodológico que orienta o cuidado profissional de enfermagem. A SAE organiza-se em cinco etapas: coleta de dados, diagnóstico de enfermagem, planejamento, implementação e avaliação de enfermagem (DA SILVA, 2015).

\section{OBJETIVO}

Desenvolver a Sistematização da Assistência de Enfermagem com uma transexual à luz do pensamento da complexidade.

\section{METODOLOGIA}

Trata-se de uma narrativa investigativa educativa, estruturada em cinco passos preconizados pelo Processo de Enfermagem, que integram a Sistematização de Assistência de Enfermagem - SAE, sendo eles: coleta de dados de enfermagem, diagnóstico, planejamento, implementação e avaliação de enfermagem. O estudo compreendeu o período de março a junho de 2019, desenvolvido com uma transexual na perspectiva da complexidade de Edgar Morin.

Inicialmente, foi realizada uma aproximação para conhecer a realidade e, assim, possibilitar o diagnóstico inicial preconizado pelo Processo de Enfermagem e delinear estratégias de intervenção. Nessa perspectiva, foram realizadas ações proativas focadas na promoção da saúde e na prevenção das IST's, diminuição do risco de agressão verbais e físicas, orientações sobre legislação e programas preventivos, garantidos por políticas públicas.

Salienta-se, que o projeto não passou pelo comitê de ética, pelo fato de se tratar de uma narrativa investigativa, desenvolvida com base nas etapas da Sistematização da Assistência de Enfermagem com uma transexual fictícia, com fins educativos e avaliativos para a disciplina de Fundamentos Téorico-Filosóficos da Enfermagem. 


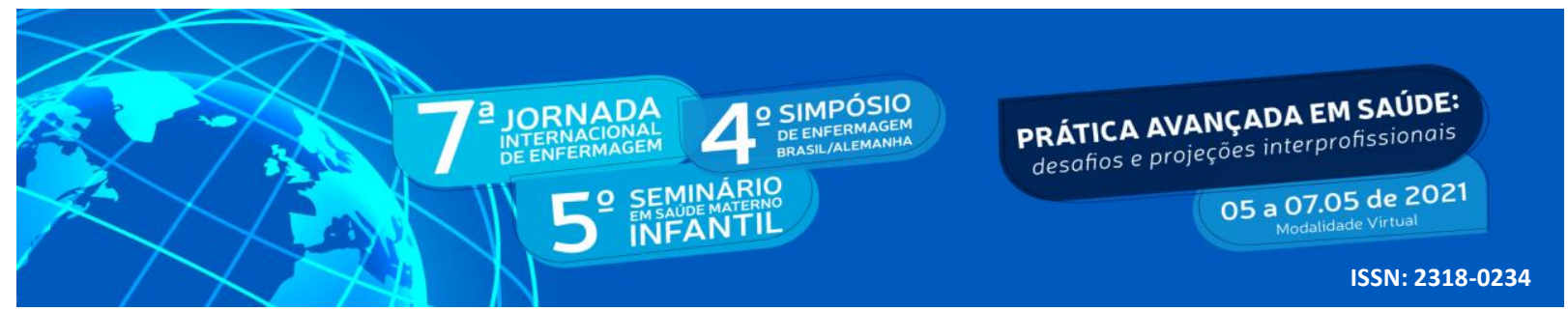

\section{RESULTADOS E DISCUSSÃO}

A SAE foi realizada com uma transexual fictícia, em cinco etapas: histórico de enfermagem, que consistiu no levantamento de informações sobre suas condições de vida, laços familiares e saúde da travesti, o diagnóstico de enfermagem norteando em um plano de cuidados através das experiências e respostas da travesti, desencadeando o planejamento e implementação com base na anamnese e diagnósticos de enfermagem, finalizando com a avaliação que consistiu em avaliar os resultados almejados.

A seguir, serão detalhados os cinco passos da Sistematização da Assistência de Enfermagem, a começar pelo Histórico de Enfermagem, conforme segue. A fim de não identificar a participante do estudo, a mesma será identificada como "Estrela Dalva".

\section{HISTÓRICO DE ENFERMAGEM}

E. D. 19 anos, divide casa juntamente com a irmã de 27 anos, em uma casa alugada com os seguintes cômodos: dois quartos, um banheiro, sala e cozinha. A casa possui saneamento básico e o aluguel é em torno de 600 reais. Sua fonte de renda é exclusivamente o da prostituição que fica em torno de 1500 a 3000 reais, sendo que esta profissão foi iniciada aos 18 anos de idade. A mesma possui uma irmã por parte de pai e 3 irmãos por parte de mãe, além de outra pessoa que considera como mãe, devido a ajuda que recebeu quando ainda era criança, com roupas e comida. Referindo que seus pais tinham condições financeiras insuficientes. Sua relação com os pais é boa e respeitosa atualmente. Quando se assumiu "gay" aos 16 anos, seu pai agrediu-a desencadeando sua saída de casa para morar com uma amiga. Desde então, mora sozinha e assumiu-se travesti com 18 anos. Possui ensino médio completo e estava cursando Técnico em Enfermagem, mas interrompeu devido ao acúmulo de dívidas. Seu primeiro emprego foi como secretária em uma clínica da sua família, e logo após trabalhou em um salão como cabeleireira, ambos empregos sem carteira assinada. Referiu ter realizado diversas entrevistas de emprego, mas nunca foi chamada. Em seu último exercício de profissão, relatou tê-lo abandonado para seguir a prostituição, pois a renda seria maior para conseguir realizar o seu sonho: procedimento cirúrgico, implante de prótese de silicone.

Realiza teste rápido para IST's (Infecções Sexualmente Transmissíveis) com frequência. Nega ser diabética e hipertensa. Refere não ser tabagista, etilista e que não possui nenhuma 


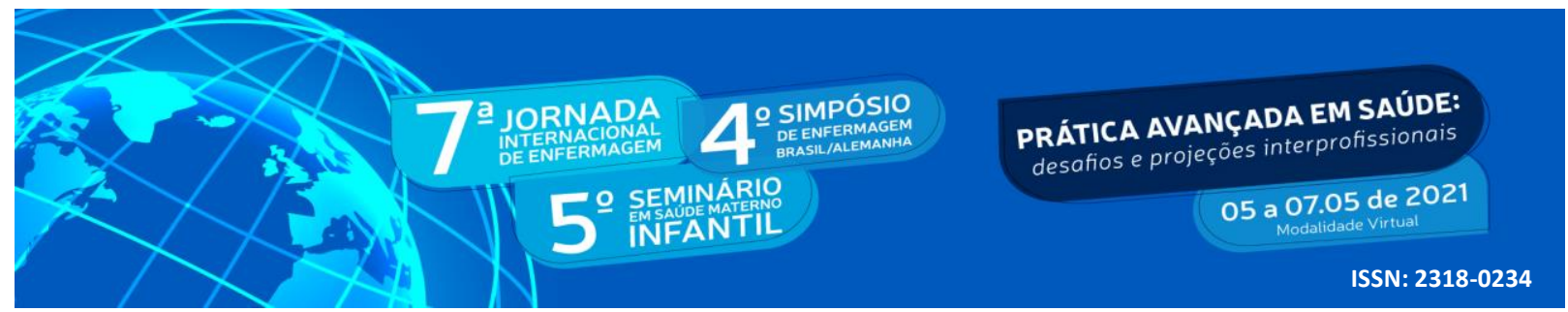

IST’s. Não utiliza drogas ilícitas. Realiza atividade física em uma academia e considera ser uma pessoa saudável e sem nenhuma patologia. Nega internação hospitalar. No entanto, relatou já ter ingerido anticoncepcional para adquirir hormônios femininos, mas encerrou logo após sentir dores de cabeça, enjoo e secreção no mamilo. Não faz uso contínuo de qualquer medicação. Refere trabalhar à noite e que viaja para algumas cidades para realizar programa. Não possui condução própria para deslocamento até o trabalho. Ela refere sofrer agressões verbais, frequentemente, bem como já ter sofrido preconceito e intolerância por parte da sociedade.

\section{DIAGNÓSTICO DE ENFERMAGEM}

Na Tabela 1, observa-se os diagnósticos de enfermagem, características definidoras e fatores relacionados, com base no livro Diagnósticos de enfermagem da NANDA-I edição 2018-2020.

Tabela 1 - Diagnósticos de Enfermagem.

\begin{tabular}{|c|c|c|}
\hline $\begin{array}{c}\text { DIAGNÓSTICOS DE } \\
\text { ENFERMAGEM }\end{array}$ & $\begin{array}{c}\text { CARACTERÍSTICAS } \\
\text { DEFINIDORAS }\end{array}$ & FATORES RELACIONADOS \\
\hline $\begin{array}{l}\text { DESEMPENHO DE } \\
\text { PAPEL INEFICAZ }\end{array}$ & $\begin{array}{l}\text { Apoio externo insuficiente para o } \\
\text { desempenho do papel; } \\
\text { Discriminação; } \\
\text { Insatisfação com o papel. }\end{array}$ & $\begin{array}{l}\text { Alteração da imagem corporal; } \\
\text { Baixa autoestima; } \\
\text { Expectativas não realistas a } \\
\text { respeito do papel; } \\
\text { Sistema de apoio insuficiente. }\end{array}$ \\
\hline DISFUNÇÃO SEXUAL & $\begin{array}{l}\text { Alteração na atividade sexual; } \\
\text { Mudança no interesse por outras } \\
\text { pessoas; } \\
\text { Mudança no papel sexual. }\end{array}$ & $\begin{array}{l}\text { Abuso psicossocial; } \\
\text { Conflito de valores; } \\
\text { Vulnerabilidade. }\end{array}$ \\
\hline
\end{tabular}




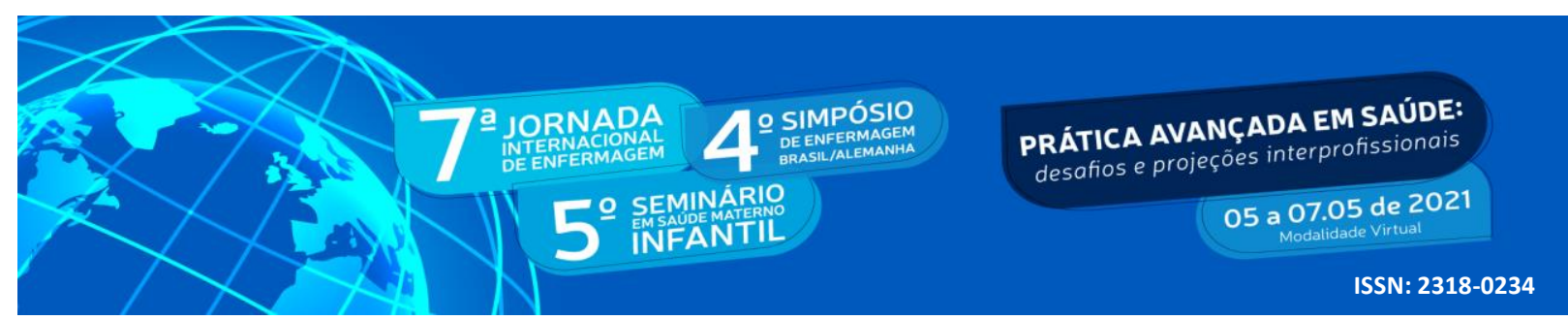

\begin{tabular}{|c|c|c|}
\hline $\begin{array}{l}\text { DISTÚRBIO NA } \\
\text { IDENTIDADE } \\
\text { PESSOAL }\end{array}$ & $\begin{array}{l}\text { Alteração da imagem corporal; } \\
\text { Confusão de gênero; } \\
\text { Desempenho de papel ineficaz. }\end{array}$ & $\begin{array}{l}\text { Alteração no papel social; } \\
\text { Discriminação; } \\
\text { Preconceito percebido; } \\
\text { Processos familiares } \\
\text { disfuncionais. }\end{array}$ \\
\hline $\begin{array}{l}\text { PADRÃO DE } \\
\text { SEXUALIDADE } \\
\text { INEFICAZ }\end{array}$ & $\begin{array}{l}\text { Alteração na atividade sexual; } \\
\text { Alteração no comportamento } \\
\text { sexual; } \\
\text { Conflito de valores; } \\
\text { Mudança no papel sexual. }\end{array}$ & $\begin{array}{l}\text { Conflito sobre orientação sexual; } \\
\text { Conhecimento insuficiente sobre } \\
\text { alternativas relacionadas à } \\
\text { sexualidade; } \\
\text { Medo de infecção sexualmente } \\
\text { transmissível. }\end{array}$ \\
\hline $\begin{array}{c}\text { ISOLAMENTO } \\
\text { SOCIAL }\end{array}$ & $\begin{array}{l}\text { Ausência de sistema de apoio; } \\
\text { História de rejeição; } \\
\text { Insegurança em público; } \\
\text { Sentir-se diferente dos outros. }\end{array}$ & $\begin{array}{l}\text { Comportamento social incoerente } \\
\text { com as normas; } \\
\text { Interesses inadequados para o } \\
\text { nível de desenvolvimento; } \\
\text { Dificuldade para estabelecer } \\
\text { relacionamentos; } \\
\text { Recursos pessoais insuficientes. }\end{array}$ \\
\hline
\end{tabular}

Fonte: HERDMAN, T. H; S. KAMITSURU. Diagnósticos de enfermagem da NANDA I:

Definições e classificações. $11^{\circ}$ Ed. Porto Alegre, Brasil, 2018.

\section{PLANEJAMENTO DE ENFERMAGEM}

O presente trabalho foi desenvolvido e planejado por um grupo de acadêmicos de enfermagem, sob o olhar do processo de Sistematização da Assistência de Enfermagem, com seu foco em acompanhar as situações diversas vivenciadas pela mesma. Foram problematizadas questões que envolviam suas atividades diárias e profissionais, assim como seu contexto social e teve como meta, identificar e relatar experiências e adversidades enfrentadas por ela, na atenção do processo da SAE.

Através da coleta de dados, foram realizados um planejamento de ações, desenvolvido por acadêmicos de enfermagem e entrevistada em questão, no âmbito de expor seus desejos, interesses e metas de vida, respeitando os passos da Sistematização da Assistência de Enfermagem (SAE), de forma que, fosse elaborada intervindo de forma positiva em sua qualidade de vida e facilitasse suas atividades diárias e profissionais. 


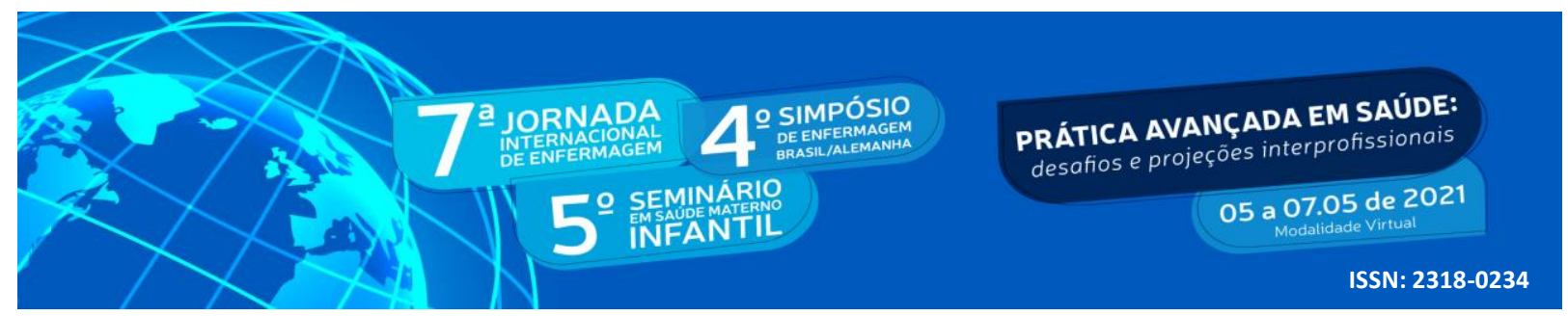

\section{INTERVENÇÕES DE ENFERMAGEM}

Foram realizadas intervenções conforme planejamento de acadêmicos e entrevistada. Como intervenção, foram propostas de forma que interviesse de forma positiva no seu cotidiano, respeitando seus desejos e interesses, sendo elas: educação permanente em relação a forma correta de utilizar preservativos, assim como o uso indiscriminado de anticoncepcionais sem avaliação médica. Diálogo sobre leis que protegem a diversidade de gênero, como: a Lei 11.340/2016, mais conhecida como Maria da Penha, que em 2006 abrangeu a esfera não só de 2 gêneros, mas sim toda a diversidade de gênero. Também foram abordadas questões familiares, como relação pai x filha: questões culturais, estigmas e pré-conceitos trazidos através de gerações.

Para sua questão socio-econômica, foi ofertado a possibilidade de elaboração de um livro para realização de suas metas, questionando a ordem de identificação do objetivo, o que seria necessário e qual caminho percorrer, estimulando a organização e formulando itinerários para sua conclusão.

\section{AVALIAÇÃO DE ENFERMAGEM}

Ao término da SAE, efetuou-se uma avaliação entre os autores deste trabalho para analisar se os resultados foram alcançados e se constatou que os resultados foram obtidos. Tal conquista deve-se à travesti que contribuiu ativamente, bem como de forma transparente, sincera e responsável na realização das etapas da SAE. Ao final do processo, a participante demonstrou contentamento ao resgatar a sua autoestima e a autoconfiança e demonstrou-se grata ao fazer uso de hidratante corporal, doado pelos acadêmicos de enfermagem.

Portanto, as travestis e transexuais são as mais sujeitas a sofrerem insultos e discriminação na família, escola, pontos de prostituição e prestadoras de serviço de saúde. Elas estão constantemente expostas a situações de rejeição e discriminação a partir do momento em que assumem a sua real identidade, este é o momento no qual sofrem ofensas, agressões físicas e verbais e principalmente aversão por parte da família (SOUZA et al, 2015).

Nesta perspectiva, Morin (2003) afirma que cada vez mais, a gigantesca proliferação de conhecimentos escapa do controle humano. Além disso, os conhecimentos fragmentados só 


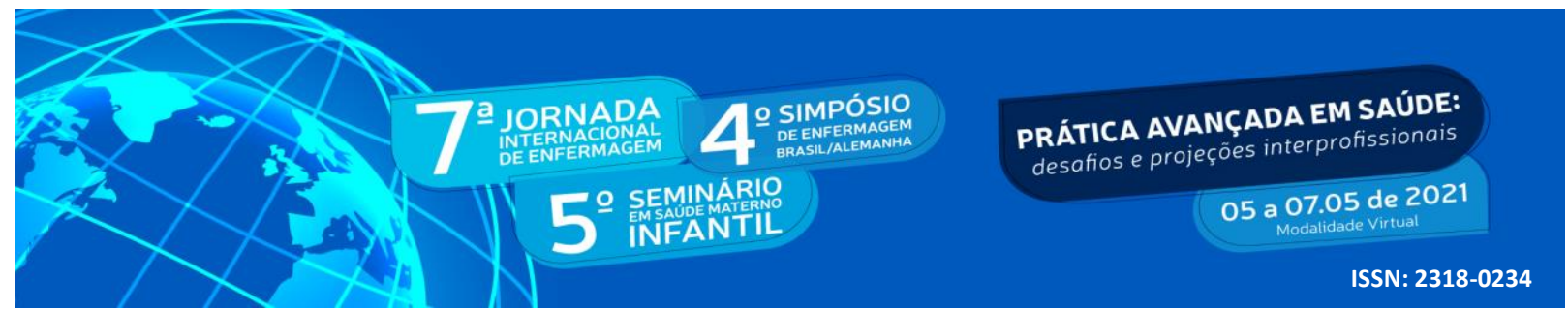

servem para usos técnicos. Não conseguimos conjugar para alimentar um pensamento capaz de considerar a situação humana no âmago da vida, na terra, no mundo, e de enfrentar os grandes desafios de nossa época.

A reflexão sobre a SAE foi fundamentada nos princípios do pensamento complexo de Edgar Morin, que segundo este o desafio da complexidade é apresentado com base na necessidade de: religar o que, habitualmente, é separado. O complexo necessita captar interrelações, realidades distintas e conflitantes, por meio de um pensamento que respeite a diversidade, buscando unir ao invés de simplificar (DA SILVA, 2015).

\section{CONCLUSÃO}

Conclui-se, que o desenvolvimento da SAE possibilitou um olhar singularizado às necessidades da travesti e a compreensão do papel social do Enfermeiro, que vai além da identificação de um problema, mas que requer intervenções proativas relacionadas à promoção da saúde.

A entrevistada em questão demonstrou boa aceitação em relação as orientações prestadas, referentes a medidas preventivas contra IST's, assim como informações sobre leis e sua aplicabilidade. Também foi discutido, sobre a possibilidade de organizar sua rotina e metas, na forma de um diário contendo itinerário por escrito, traçando novas metas com ideia objetiva de superá-las. O estudo demonstra a necessidade de um maior envolvimento no contexto social das travestis, percebendo que é uma população em situação de vulnerabilidade social específica e são expostas frequentemente a diferentes tipos de agressões sociais e familiares.

O diálogo informal e presencial com a entrevistada, tornou mais acessível alcançar as informações acima referidas, evidenciando a presença do entrevistador, assim como seu gênero, sendo do segmento feminino, de suma importância, tornando a coleta mais aberta e informal. Como opinião dos pesquisadores do trabalho, acredita-se que um número maior de entrevistados, se reunindo como um grupo em ambiente particular e restrito para formulação do mesmo, e também, um número maior de profissionais para aplicar a entrevista, surtiram um resultado mais amplo.

O estudo desencadeou outro disparador. Os serviços assistenciais em sua ampla grade interdisciplinar e multiprofissional, estariam prontos e capacitados para receber a população em 


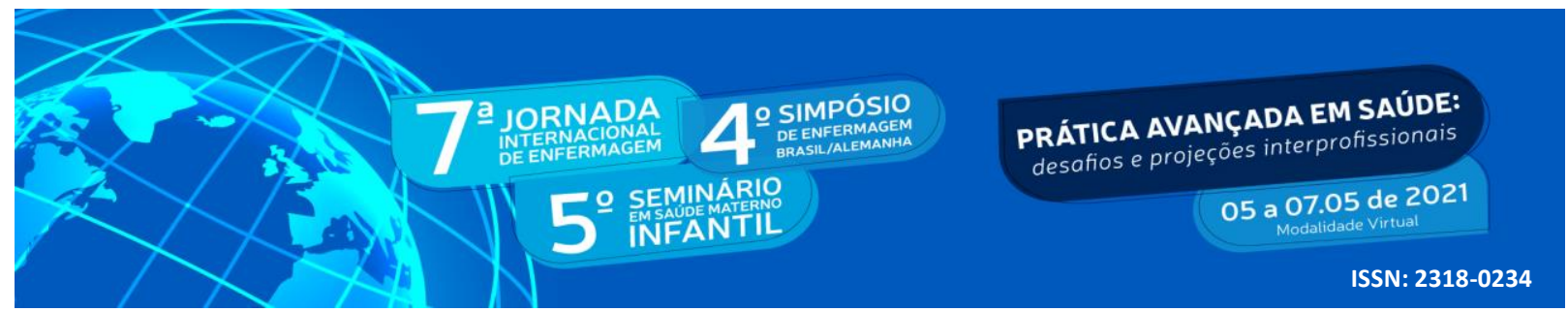

sua diversidade de gênero? O ponto frágil do estudo, se apresenta na coleta de dados com a entrevistada, não aceitando a participação do segmento masculino na entrevista.

\section{REFERENCIAS}

BENTO, B. A reinvenção do corpo: sexualidade e gênero na experiência transexual. $2^{\circ} \mathrm{Ed}$. Natal: EDUFRN, 2014.

BRASIL. Ministério Da Saúde. Plano nacional de enfrentamento da epidemia de aids e das DST entre gays, HSH e travestis. Brasília: MS; 2007.

CURY, C. A. "Transexualismo: da mitologia à cirurgia". 1ª Ed. São Paulo, 2012.

DA SILVA, J. "Sistematização da Assistência de Enfermagem na graduação: um olhar sob o Pensamento Complexo". Rev. Latino-Am. Enfermagem. Londrina, PR, Brasil, 2015. Disponível em: http://www.scielo.br/pdf/rlae/v23n1/pt_0104-1169-rlae-23-01-00059.pdf. Acesso em: 21 de junho de 2019.

HERDMAN, T. H; S. KAMITSURU. Diagnósticos de enfermagem da NANDA I: Definições e classificações. $11^{\circ}$ Ed. Porto Alegre, Brasil, 2018.

MORIN, E. A cabeça bem-feita: repensar a reforma, reformar o pensamento. $22^{a}$ Ed. Rio de Janeiro, Brasil, 2015.

MORIN, E. A via para o futuro da humanidade. $2^{\text {a }}$ Ed. Rio de Janeiro, Brasil, 2015.

SOUZA, M. H. T. et al. "Violência e sofrimento social no itinerário de travestis de Santa Maria, Rio Grande do Sul, Brasil”. Cad. Saúde Pública, Rio de Janeiro, v. 31, n. 4, p. 767-776, abril. 2015. Disponível em: https://www.scielo.br/pdf/csp/v31n4/0102-311X-csp-31-04-00767.pdf. Acesso em: 21 de junho de 2019. 